\title{
Perancangan Mobile Manipulator Robot Secara Simulasi Menggunakan Microsoft Robotics Developer Studio
}

\author{
MILDA GUSTIANA ${ }^{1}$, YOULLIA INDRAWATY ${ }^{2}$, ARRY FEBRIANDI ${ }^{3}$ \\ Institut Teknologi Nasional \\ Email : mghusada@itenas.ac.id
}

\begin{abstract}
ABSTRAK
Mobile Manipulator Robot merupakan suatu jenis robot yang terdiri atas bagian mobilitas (mobile) dan bagian manipulator. Pemanfaatan robot jenis ini antara lain dalam hal keamanan misalnya untuk mengambil dan mengangkut benda berbahaya. Simulasi dilakukan untuk mengurangi kesalahan saat proses perancangan yang dapat terjadi sepert dalam hal perancangan fisik maupun pada pemrograman. Pada penelitian ini dilakukan perancangan mobile manipulator robot dengan methodology for robotic simulation dan disimulasikan menggunakan Microsoft Robotics Developer Studio. Bagian manipulator dari robot yang dirancang memiliki 6 DOF. Simulasi yang dihasilkan menunjukkan kesesuaian dengan rancangan yang dibuat.
\end{abstract}

Kata kunci: Mobile manipulator robot, Simulasi, Microsoft robotics developer studio.

\begin{abstract}
A Mobile Manipulator Robot is a robot that has mobile part and manipulator part. One use of this kind of robot is for safety such as picking and delivering dangerous object. Simulation is conducted to minimize error at design process that could be occured such physical design or programming. This paper shows the design of mobile manipulator robot by using methodology for robotic simulation, and developed simulation by using Microsoft Robotics Developer Studio. Manipulator part of the robot has 6 DOF. Simulation result shows similarity with the design.
\end{abstract}

Keywords: Mobile manipulator robot, Simulation, Microsoft robotics developer studio. 


\section{PENDAHULUAN}

\subsection{Latar Belakang Masalah}

Mobile manipulator robot merupakan gabungan dua buah robot yaitu mobile robot dan manipulator robot. Robot jenis ini sangat dibutuhkan terutama dari dunia militer untuk keperluan mengangkat serta memindahkan benda berbahaya.

Dalam merancang sebuah robot ada dua kemungkinan kesalahan yang akan terjadi, kesalahan desain fisik robot dan logika pemrograman. Kesalahan logika pemrograman dapat dengan mudah diatasi, sedangkan kesalahan desain fisik robot akan memakan waktu serta biaya untuk memperbaiki.

Microsoft robotics developer studio menawarkan fasilias simulasinya untuk dapat melakukan perancangan robot serta pengujicobaan robot tersebut. Microsoft robotics developer studio menggunakan Physic engine sehingga simulasi dapat menyerupai keadaan dunia sebenarnya.

\subsection{Rumusan Masalah}

Rumusan masalah yang dapat diambil adalah bagaimana tahapan tahapan yang digunakan untuk merancang suatu robot dan bagaimana tahapan yang digunakan untuk mensimulasikan rancangan tersebut dalam simulator.

\subsection{Tujuan Penelitian}

Adapun tujuan penelitian yang akan dicapai adalah dirancangnya sebuah mobile manipulator robot. Rancangan tersebut disimulasikan dalam ruang simulator sehingga dapat memudahkan untuk melakukan rangkaian pengujian terhadap robot tersebut.

\section{LANDASAN TEORI}

\subsection{Mobile manipulator robot}

Istilah mobile manipulator robot pada saat ini mengacu pada sebuah sistem robot yang terdiri dari manipulator robot yang terpasang pada mobile robot. sistem tersebut menggabungkan keuntungan dari mobile robot dan manipulator robot dan mengurangi kelemahan mereka. Mobile manipulator memberikan dua keunggulan yaitu mobilitas yang diberikan mobile robot dan ketangkasan yang diberikan manipulator robot. Mobile manipulator robot merupakan penggabungan dari 4 komponen utama yaitu Mobile robot, Manipulator robot, Vision dan Tooling seperti yang terlihat pada Gambar 1.

\subsection{Methodology for robotics Simulation}

Terdapat 8 fasa yang digunakan pada methodology for robotics simulation seperti yang terlihat pada Gambar 2.

Keuntungan menggunakan metodologi ini adalah dengan menggunakan metodologi ini akan membuat rancangan dan implementasi robot dalam simulasi lebih terstruktur dan dapat menghemat biaya untuk merancang, membangun, menguji robot kembali yang akan menyebabkan proyek robot tersebut mahal. 


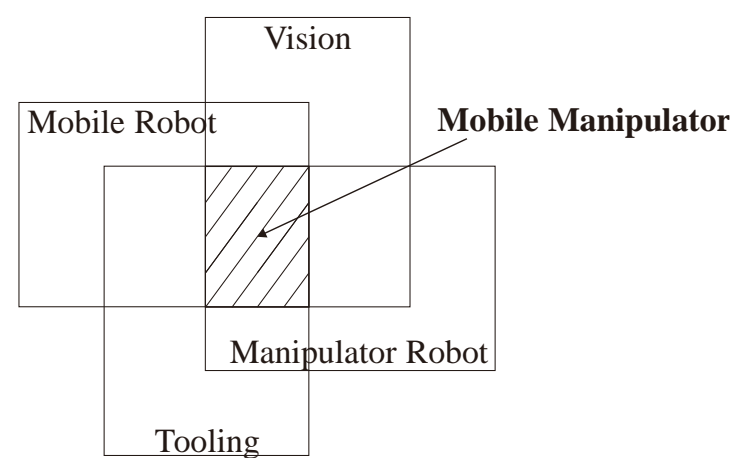

Gambar 1. Mobile manipulator System (Sumber: The Mobile robot "Little Helper"; Concepts, ideas and working principles, 2009)

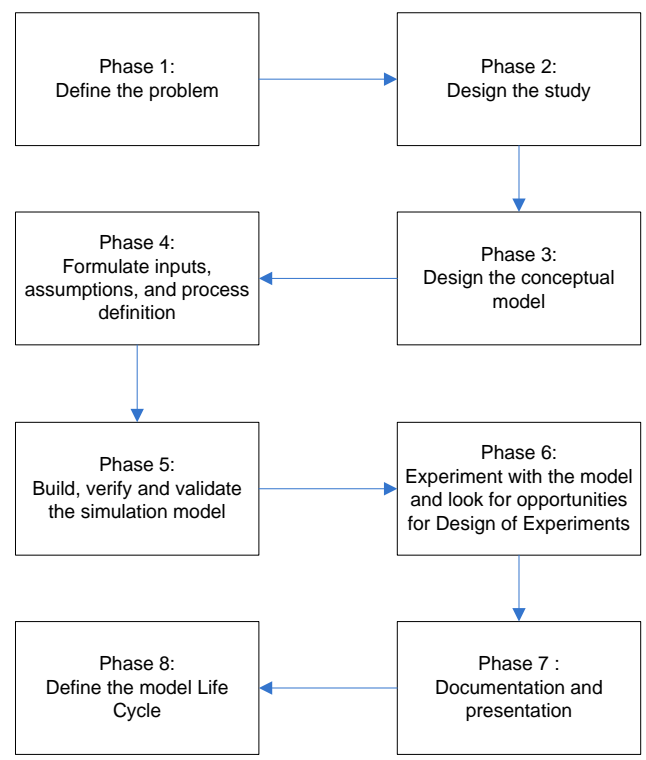

Gambar 2. Methodology For robotics Simulation (Sumber : robotic modeling and simulation: theory and application. 2009)

\section{PERANCANGAN}

\subsection{Konseptual Mobile manipulator robot}

Mobile manipulator robot yang dirancang merupakan gabungan dari 2 robot yaitu mobile robot dan manipulator robot. mobile robot dirancang menggunakan efektor tracked. penggunaan efektor tracked ini didasari karena kemampuan tracked yang dapat melintasi berbagai kondisi lingkungan, terutama lingkungan yang kasar dan licin. Manipulator robot dirancang merupakan manipulator robot dengan 4 lengan dan menggunakan effektor berupa handgrip. Effektor handgrip digunakan untuk dapat mengangkat serta memindahkan benda.

Berdasarkan konseptual diatas dirancang mobile manipulator robot yang diilustrasikan pada Gambar 3. 


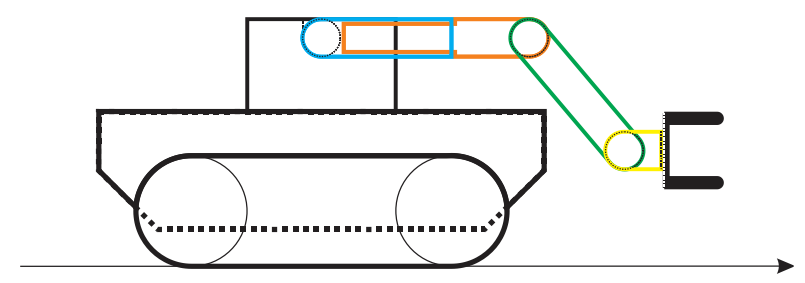

\section{Gambar 3. Rancangan Mobile manipulator robot}

\subsection{Pergerakan Mobile manipulator robot}

Pergerakan mobile manipulator robot terdiri atas 2 gerakan robot, gerakan mobile robot dan gerakan manipulator robot. Bagian Mobile robot memiliki 6 gerakan yaitu (a)Forward, yaitu gerakan robot berjalan ke arah depan; (b) Backward, yaitu gerakan robot berjalan ke arah belakang; (c) Turn Right, yaitu gerakan robot berbelok ke arah kanan; (d) Turn left, yaitu gerakan robot berbelok ke arah kiri; (e)Rotate right, yaitu gerakan robot berputar ke arah kanan (searah jarum jam); (f)Rotate left, yaiut gerakan robot berputer ke arah kiri (berlawanan arah jarum jam). Penjelasan setiap bagian mobile robot diberikan oleh Tabel 1.

\section{Tabel 1. Rancangan Pergerakan Manipulator robot}

\begin{tabular}{ll}
\multicolumn{1}{c}{ Jenis mobilitas } & \multicolumn{1}{c}{ Penjelasan } \\
Forward & $\begin{array}{l}\text { Gerakan robot berjalan ke arah } \\
\text { depan (maju) } \\
\text { Gerakan robot berjalan ke arah } \\
\text { belakang (mundur) }\end{array}$ \\
Turn Right & $\begin{array}{l}\text { Gerakan robot berbelok ke arah } \\
\text { kanan }\end{array}$ \\
Turn left & Gerakan robot berbelok ke arah kiri \\
Rotate right & $\begin{array}{l}\text { Gerakan robot berputar ke arah } \\
\text { kanan (searah jarum jam) } \\
\text { Rotate left }\end{array}$ \\
& $\begin{array}{l}\text { Gerakan robot berputer ke arah kiri } \\
\text { (berlawanan arah jarum jam) }\end{array}$
\end{tabular}

Manipulator robot memiliki gerakan 6 DOF dan gerakan Hand Grip, seperti yang terlihat pada Tabel 2.

Tabel 2. Rancangan Pergerakan Manipulator robot

$\begin{array}{lccc}\text { Gerakan } & \text { Jenis gerakan } & \text { Min } & \text { Max } \\ \text { DOF } 1 & \text { Angular } & -180^{\circ} & +180^{\circ} \\ \text { DOF } 2 & \text { Linear } & 0 \mathrm{~cm} & 15 \mathrm{~cm} \\ \text { DOF } 3 & \text { Angular } & 0^{\circ} & 90^{\circ}\end{array}$




$\begin{array}{lccc}\text { DOF } 4 & \text { Angular } & 0^{\circ} & 180^{\circ} \\ \text { DOF } 5 & \text { Angular } & -90^{\circ} & 90^{\circ} \\ \text { DOF 6 } & \text { Angular } & -180^{\circ} & 180^{\circ} \\ \text { Handgrip } & \text { Linear } & 5 \mathrm{~cm} & 5 \mathrm{~cm}\end{array}$

\subsection{Rancangan Sistem Simulasi}

Sistem simulasi pada penelitian ini menggunakan Microsoft Robotics Developer Studio 4. Sistem simulasi menggunakan 5 services seperti yang terlihat pada Gambar 4.

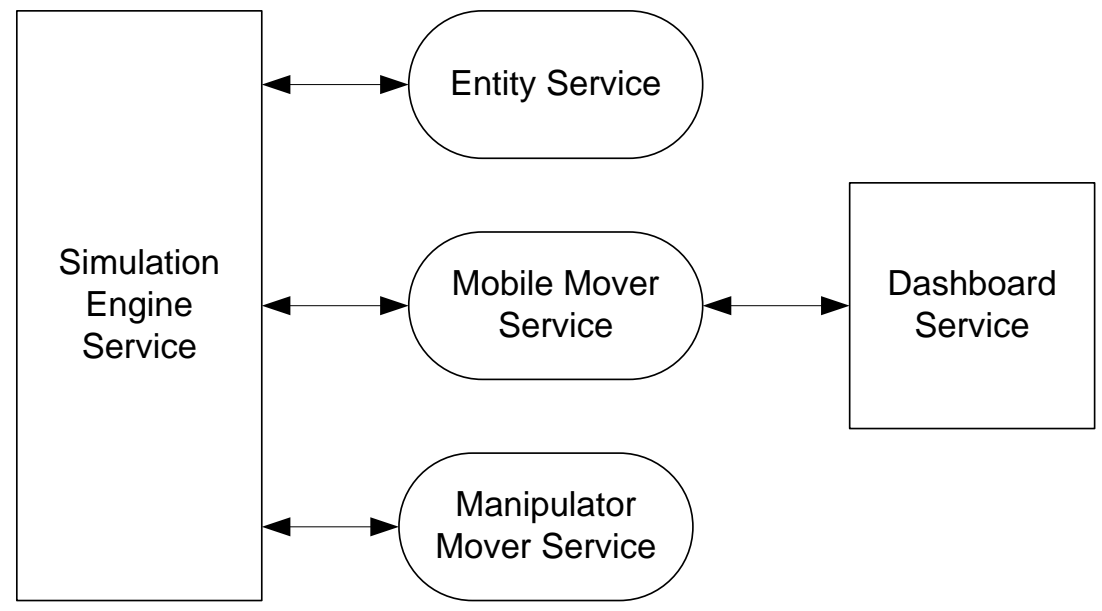

Gambar 4. Rancangan Sistem

Entity Service merupakan pusat penelitian simulasi ini. Services ini berisikan data data konfigurasi robot, lingkungan serta pergerakan.

Mobile Mover Service merupakan services yang diberikan oleh Microsoft Robotics Developer Studio sebagai sampel, services ini berisikan data data untuk menggerakkan mobile robot. services ini tidak memiliki user interface sehingga dibutuhkan Dashboard Service sebagai interface pergerakan.

Manipulator mover service merupakan services yang diberikan oleh Microsoft Robotics Developer Studio sebagai sampel, service ini berisikan data untuk menggerakkan manipulator robot. services juga menyediakan interface berupa slider untuk menggerakkan robot.

Seluruh data dari services di atas dikumpulkan oleh Simulation Engine Service. Services ini merupakan services yang menampilan hasil simulasi.

\section{IMPLEMENTASI}

\subsection{Impelentasi Mobile manipulator robot}

Berdasarkan data dari perancangan hasil yang didapat dari simulasi adalah gambaran mobile manipulator robot seperti yang terlihat pada Gambar $\mathbf{5}$. 
Dalam implementasinya, mobile manipulator robot terdiri dari dua bagian robot yaitu mobile robot dan manipulator robot. bentuk robot yang diimplementasikan ke dalam simulator merupakan bentuk benda dasar. Bentuk tersebut digunakan untuk menggambarkan bentuk dasar robot tersebut. Untuk mendapatkan gambar yang terlihat lebih nyata dapat digunakan mesh $3 D$ yang dapat diperoleh dari aplikasi pembuat gambar 3D (3-dimensi) seperti Maya, 3D Studio max dan Blender utntuk membungkus objek dasar tersebut. Mobile robot terdiri dari dua bagian utama yaitu badan robot dan efektor penggerak robot. Badan mobile robot merupakan penopang utama mobile robot sekaligus tempat diletakkannya manipulator robot. perbandingan rancangan dan bentuk dasar badan mobile robot terlihat pada Gambar 6 .

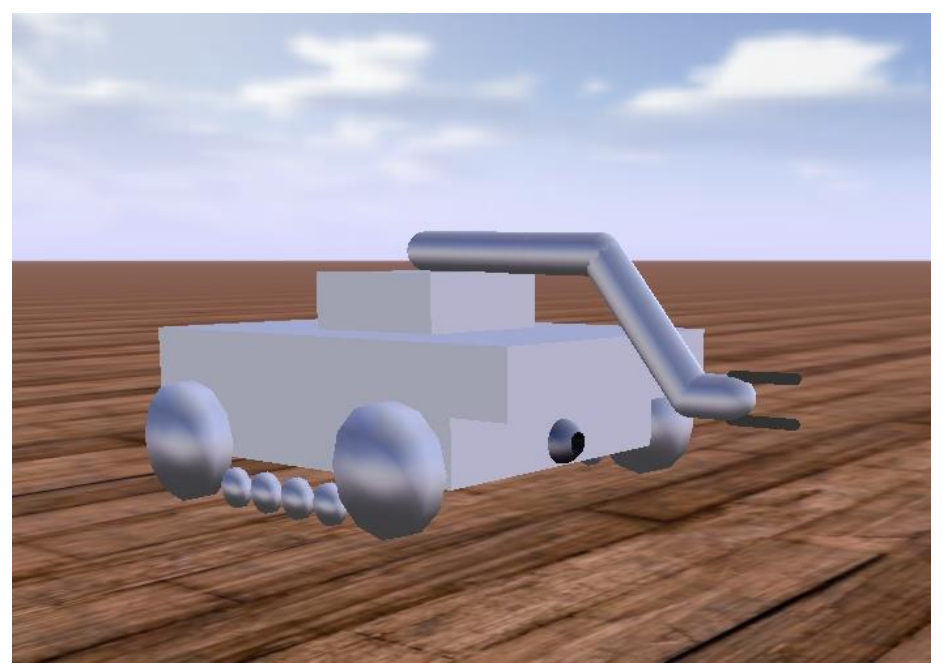

Gambar 5. Hasil Simulasi Mobile manipulator robot

Gambar Rancangan

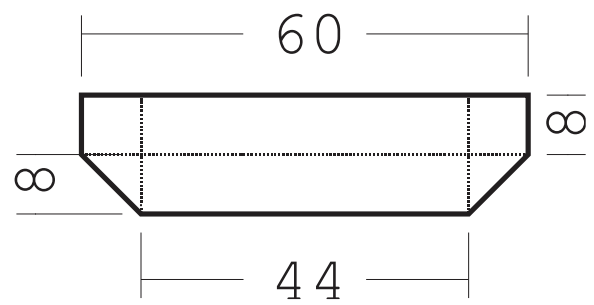

Bentuk dasar implementasi

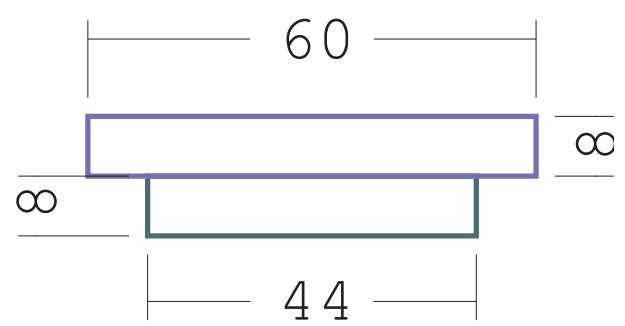

Gambar 6. Rancangan dan Rancangan implementasi badan mobile robot

Efektor penggerak mobile robot dirancang menggunakan efektor berupa tracked. tetapi Agiea PhysX sebagai penyedia physic engine hanya menyediakan penggerak berbentuk bulat atau roda. Untuk itu digunakan roda kecil tambahan sebagai pengganti belt pada tracked. Perbandingan rancangan efektor mobile robot dan rancangan implementasi efektor mobile robot terlihat pada Gambar $\mathbf{7}$. 
Gambar Rancangan

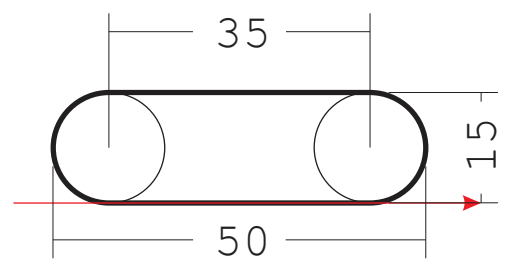

Bentuk dasar implementasi

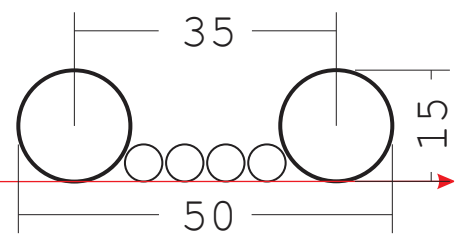

\section{Gambar 7. Rancangan dan rancangan implementasi efektor mobile robot}

Manipulator robot yang dirancang memiliki 6 bagian yaitu base manipulator robot, lengan 1, 2, 3, 4 dan efektor handgrip. Perbandingan rancangan dan bentuk dasar pada implementasi dapat terlihat pada Gambar 8.

Gambar rancangan

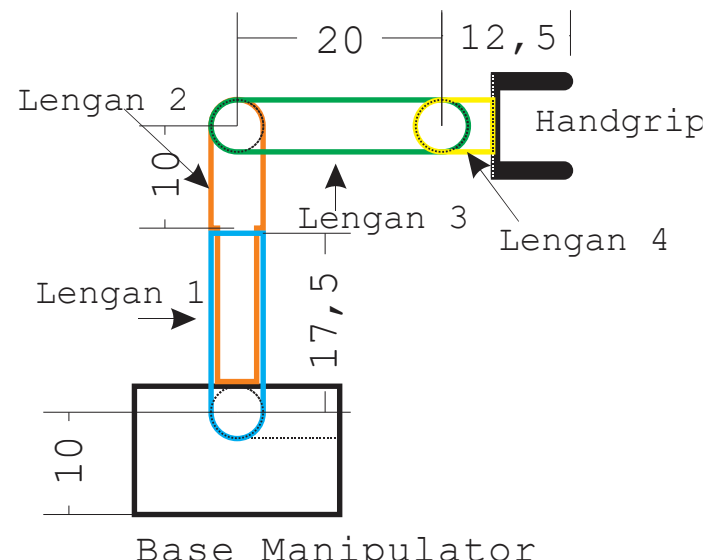

Bentuk dasar implementasi

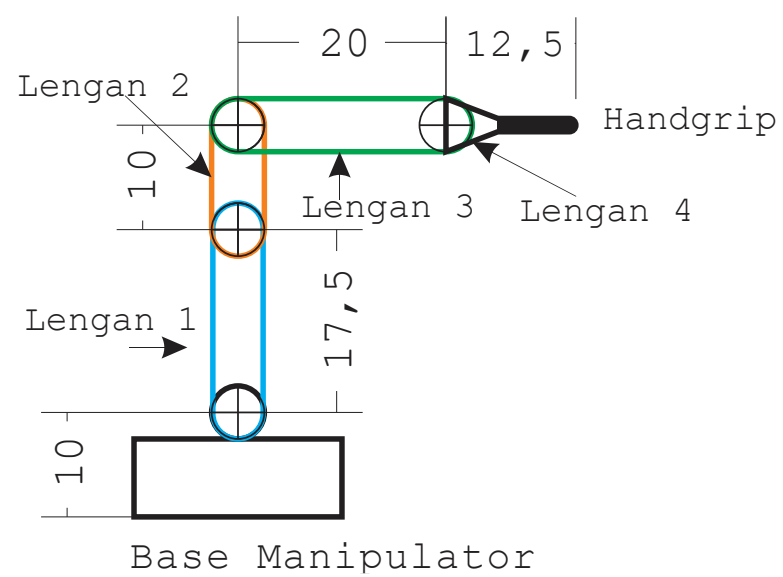

Gambar 8. Rancangan dan rancangan implementasi manipulator robot

\subsection{Validasi Pergerakan}

Berdasarkan pengamatan simulasi, dilakukan pengamatan pada pergerakan robot. Hasil Validasi pergerakan mobile robot tertera pada Tabel 3, dan validasi pergerakan manipulator robot tertera pada Tabel 4.

Tabel 3. Validasi pergerakan mobile robot

\begin{tabular}{llc}
\multicolumn{1}{c}{ Yang diharapkan } & \multicolumn{1}{c}{ Hasil uji } & Kesimpulan \\
Robot bergerak arah depan & Robot bergerak arah depan & Valid \\
Robot bergerak arah belakang & Robot bergerak arah belakang & Valid
\end{tabular}




$\begin{array}{llr}\text { Robot berbelok arah kanan } & \text { Robot berbelok arah kanan } & \text { Valid } \\ \text { Robot berbelok arah kiri } & \text { Robot berbelok arah kiri } & \text { Valid } \\ \text { Robot berputar arah kanan } & \text { Robot berputar arah kanan } & \text { Valid } \\ \text { Robot berputar arah kiri } & \text { Robot berputar arah kiri } & \text { Valid }\end{array}$

Tabel 4. Validasi pergerakan manipulator robot

\begin{tabular}{lcccccc} 
Gerakan & $\begin{array}{c}\text { Jenis } \\
\text { Gerakan }\end{array}$ & \multicolumn{2}{c}{ Yang diharapkan } & \multicolumn{2}{c}{ Hasil uji } & Kesimpulan \\
& Min & Max & Min & Max & \\
\hline DOF 1 & Angular & $-180^{\circ}$ & $+180^{\circ}$ & $-180^{\circ}$ & $+180^{\circ}$ & Valid \\
DOF 2 & Linear & $0 \mathrm{~cm}$ & $15 \mathrm{~cm}$ & $0 \mathrm{~cm}$ & $1 \mathrm{~m}$ & Invalid \\
DOF 3 & Angular & $0^{\circ}$ & $90^{\circ}$ & $0^{\circ}$ & $90^{\circ}$ & Valid \\
DOF 4 & Angular & $0^{\circ}$ & $180^{\circ}$ & $0^{\circ}$ & $180^{\circ}$ & Valid \\
DOF 5 & Angular & $-90^{\circ}$ & $90^{\circ}$ & $-90^{\circ}$ & $90^{\circ}$ & Valid \\
DOF 6 & Angular & $-180^{\circ}$ & $180^{\circ}$ & $-180^{\circ}$ & $180^{\circ}$ & Valid \\
Handgrip & Linear & $-5 \mathrm{~cm}$ & $5 \mathrm{~cm}$ & $-1 \mathrm{~m}$ & $1 \mathrm{~m}$ & Invalid
\end{tabular}

\section{KESIMPULAN}

Kesimpulan yang dapat diambil pada penelitian ini bahwa:

1. Bentuk fisik mobile manipulator robot telah diimplementasikan dengan baik pada simulator.

2. Agiea PhysX sebagai penyedia physic engine hanya menyediakan penggerak berbentuk roda, sehingga fungsi belt pada aktuator tracked digantikan oleh penambahan roda.

3. Dengan menggunakan mobile mover service, pergerakan mobile robot telah berjalan sesuai rancangan.

Dengan menggunakan manipulator mover service, pergerakan dengan jenis angular dapat berjalan dengan baik, meskipun terjadi kesalahan pada pergerakan jenis linear di bagian handgrip.

\section{DAFTAR RUJUKAN}

[1] M. Hvilshøj, S. Bøgh, O. Madsen and M. Kristiansen. (2009). The Mobile robot "Little Helper": Concepts, ideas and working principles. Dalam 14th IEEE International Conference on Emerging Techonologies and Factory Automation. 
[2] Muhammad Ikhwan Jambak, Habibollah Haron, Helmee ibrahim, Norzahlan Abd Hamid. (2009) Robotic modeling and simulation: Theory and Application. Dalam Asia International Confrence on modelling and simmulation.

[3] Johns, Kyle. Taylor, Trevor. (2008). Microsoft ${ }^{\circledR}$ Robotics Developer Studio. Indianapolis: Wiley Publishing, Inc 
Perancangan Mobile Manipulator Robot Secara Simulasi Menggunakan Microsoft Robotics Developer Studio 